\title{
A FOTOGRAFIA NA PINTURA ESPETACULAR DE PEDRO AMÉRICO
}

\author{
Pintor e Prof. Dr. Vladimir Machado
}

Escola de Belas Artes - Universidade Federal do Rio de Janeiro (EBAUFRJ)

Considerada pela estética modernista por todo século XX, como uma pintura "pompier" e de mau gosto acadêmico, a tela da Batalha do Avaí de Pedro Américo(1843-1905), ficou no ostracismo, afastada de qualquer olhar crítico mais aprofundado sobre aquela imensa e grandiosa representação . O crítico modernista Sergio Milliet (1898-1966) no seu livro "Pintura sempre" no capítulo batalhas, não destinou uma linha sequer sobre as maiores pinturas deste gênero já feitas no Brasil, fossem as obras de Vitor Meirelles ou as criadas por Pedro Américo.

A historiografia sobre o artista contra-atacava o silêncio e o desprezo modernista. Exposições e livros faziam a defesa reacionária de que o pintor tratava-se de um grande artista acadêmico e conservador dos postulados e regras tradicionais das antigas academias. Nada mais confuso e enganoso. Na verdade Pedro Américo desempenhava o papel de um artista moderno para a sua época, engajado nos dois temas mais polêmicos do séc. XIX. Por um lado tinha uma posição clara contra o idealismo e as regras neo-clássicas das academias, lutando por reformas e por outro, era um defensor do uso de fotografias para pintar e renovar o gênero mais prestigioso da época ,a Pintura de História.

É imperdoável esquecer que o jovem artista estava estudando em Paris entre 1860 e 1864 e teve a oportunidade de acompanhar a polemica sobre arte e fotografia e as transgressões contra a pintura erudita de gênero histórico idealista da Academia. Ele visitou o polemico Salão dos Recusados em 1863, e viu as novidades na pintura ,tanto as feitas por E. Manet (18321883), com seu escandaloso "Almoço na relva", quanto pelos artistas realistas e românticos . Mas Pedro Américo não ficou só na contemplação passiva das obras. O pintor brasileiro, então com 20 anos de idade, se batia contra os rígidos padrões acadêmicos e escrevia um manifesto contra o pintor neoclássico Dominique Ingres (1780-1867) e a "severidade tirânica" da Escola de Belas Artes de Paris, a qual obrigava os artistas a serem meros "imitadores dos gregos". Além disso, condenava com veemência as 
pinturas para o Premio de Roma dos pintores acadêmicos, considerando-as um pálido reflexo da civilização.

Pedro Américo pregava mudanças radicais, colocando ênfase em um pluralismo cultural. Para ele, uma academia deveria apresentar aos seus alunos todas as doutrinas, mesmo as mais opostas. Defendia portanto, a originalidade pessoal do artista, a qual não devia ser sacrificada à nenhuma escola , à nenhuma doutrina estética exclusiva. Enfim, o artista devia assumir o "espírito novo" da modernidade de sua época, afastando-se da facção "bastarda e desencorajante" das idéias acadêmicas, clássicas e conservadoras . Para um pintor de história como P. Américo, a luta pela independência desses padrões de pureza acadêmicos, passava pela possibilidade de utilizar a fotografia como um modelo de representação mais realista na sua pintura.

\section{Uma obsessão dos pintores e fotógrafos: representar com realismo o movimento}

Diante desse manifesto contra a academia , a favor da arte e industria e de considerar a invenção da fotografia "positiva e fundamental" para a pintura de história, foi igualmente notável descobrir que o artista de fato apropriou-se de fotografias para pintar. Tomando a fotografia como modelo, o pintor agia como se fosse um repórter fotográfico, tornando a pintura da Batalha do Avahi visualmente diferente da pintura idealista tradicional.

Nos anos de 1860, a fotografia congelando um instante da ação, que o olho não via, apenas sugeria aos pintores a possibilidade de fixar um movimento humano, em poses reais, as quais não correspondiam as já vistas na pintura dos grandes mestres conhecidos na História da Arte. Apesar deste avanço, a fixação sofisticada e de múltiplos efeitos de uma imagem em movimento rápido, como vemos hoje no cinema, televisão e até em celulares, ainda era um sonho distante que a fotografia prometia oferecer. Para melhor compreender a tarefa a que se propôs o pintor Pedro Américo, devemos lembrar o desenvolvimento paralelo, desde 1872 até o final do séc.XIX, das experiências de Eadweard Muybridge (1830-1904) em Sacramento, na Califórnia e do cientista francês Etienne-Jules Marey (18301904), em Paris. Ambos moveram uma intensiva busca técnica para a fotografia fixar o movimento instantâneo, nesta época ainda uma quimera.

Em uma busca desenfreada por um panrealismo, a indústria produzia máquinas fotográficas que passaram a fixar uma imagem em 
segundos. O desenvolvimento técnico das câmeras e da química diminuíram o tempo de exposição da imagem à luz, o que permitiu aos dois pesquisadores fixar com máxima definição, o movimento de um instante do caminhar humano e animal, nunca visto nas representações pictóricas. Essas fotografias fora dos padrões, tiveram um enorme impacto para os pintores de história, notável em várias obras, principalmente na década de 1880. Os pintores de batalhas dispunham agora de imagens de animais e pessoas em movimento, não segundo os cânones e modelos estéticos da arte grega e dos velhos mestres, mas segundo as fotografias de Muybridge.

A partir desse momento, pelas provas visuais nunca antes registradas, toda a tentativa de representação realista do movimento pelos pintores ,também era passível de comparação com os desenhos feitos a partir das fotos de Muybridge nos periódicos americanos e franceses de 1878 e 1879. Pelas datas, evidentemente, Pedro Américo não viu estas fotografias enquanto pintava a Batalha do Avaí, entre 1875 e 1876. Mas é aceitável pensar que a acentuação exagerada nos detalhes do movimento real, pintados por Pedro Américo, fosse devido à divulgação das experiências das fotos de Muybridge e de Marey desde 18731. Sem ter acesso às fotos de Muybridge, Pedro Américo teria sido estimulado pelas informações escritas e usado as fotos estáticas, compradas em Florença e em Paris, para servirem de aides-mémoire para pintar o movimentado painel.

Esse clima cultural reforçava os objetivos de Pedro Américo em captar o instante fugaz de um corpo em movimento, e que a máquina fotográfica se aproximava por registrar com todo o realismo. $\mathrm{Na}$ Batalha do Avaí, essa obsessão em fixar uma imagem pictórica como se captada em um "golpe-de-vista" fotográfico, atingiu o clímax em vários pontos da composição. Destacaremos apenas um deles,que consideramos notável. Trata-se do cavalo pintado a partir de uma fotografia, localizado à esquerda na cena onde se encontra o General Osório. Esta fotografia pertencia à coleção do pintor, possivelmente adquirida a partir de março de $1875 .^{2}$ É

1 Étienne Jules - Marey publicou em 1873 em Paris, La macbine animale, locomotion terrestre et aérienne com 117 figuras. Em 1872-1873, jornais de S. Francisco, como o Bulletin, a Chronicle e o Post haviam tornado notável o fato das experiências fotográficas do movimento, feitas por Muybridge. Cf. Hendrick,G. Eadweard Muybridge - the father of the Motion Picture, Dover Publications,Inc. 2001,271p.:iI. p.100.

2 Trata-se de uma foto de cavalo de autoria de C. Famin - photographe - Paris - colada em cartão verde, tendo no verso o carimbo da Photographie Artistique A.Foucelle, Rue du Seine, 6, Paris. Dim. 12 X 15 aprox. (pasta 44, arquivo do MNBA-RJ). 
uma fotografia curiosa de um cavalo branco, de costas, sem ser possível divisar-lhe a cabeça. A sua cauda, tendo feito um movimento muito rápido, tornou impossível a fixação desse movimento pela fotografia, dando ao cavalo estranho aspecto como se não tivesse cauda, mostrando bem os detalhes anatômicos. A transposição para a pintura acentuou a estranheza desse escorço absolutamente original na representação de cavalos. A fotografia, servindo como referência para a memória, possibilitou a Pedro Américo pintar na Batalha do Avahí, não o cavalo estático, mas a suspensão de um instante em que todo o peso do animal estava flutuando com as quatro patas no ar, antes de voltar a tocar o chão. $O$ extraordinário movimento do cavalo, pintado a partir da inusitada e estranha fotografia, criava uma imagem fora dos padrões. Hoje esta imagem seria comum.Mas na época foi tão gritante essa novidade, que um crítico de pseudônimo Nullius escrevia em um dos principais jornais do Rio de Janeiro, a Gazeta de Noticias, atacando as mudanças modernas da pintura durante a primeira exposição da obra na capital do império, em setembro 1877. Acusava Pedro Américo de ter usado o expediente de pintar o cavalo com o seu "movimento natural", dando a aparência de realmente estar no ar, apenas com o objetivo de encantar e seduzir o público apelando para as espetaculares e vulgares ilusões óticas . O crítico considerava um defeito o cavalo estar de costas para o observador, galopando ilusoriamente para dentro do quadro. Para ele, esta posição foi escolhida por Pedro Américo só para que "..bem visivel se tornasse essa agilidade e leveza pela moleza das articulacõos das patas posteriores”, e a nosso ver, desviando a atenção do espectador para a novidade da hábil solução fotográfica da pintura a qual causava um forte e impressionante impacto visual. ${ }^{3}$ A crítica idealista desta época temia que a prestigiosa e elevada Pintura de História fosse reduzida a um simples e vulgar espetáculo de ilusões óticas, como nos Panoramas, no visor estereoscópico ou nas Fantasmagorias muito populares no Rio de Janeiro.

Indignado com os novos padrões artísticos trazidos por Pedro Américo ao Brasil, Nullius condenava as novidades de cor e composição dinâmica como estando fora das regras acadêmicas da "verdadeira arte" e do "bom gosto" ideal. Atacava ainda o fato do artista procurar ostentar na pintura a "...beleza real [da fotografia] e com algum ideal". O crítico podia não gostar, mas era essa a aspiração maior dos pintores de história mais avançados da época. Não utilizá-los era ir contra a "modernidade" da

\footnotetext{
3 Nullius. Gazeta de Notícias, 29 set. e 2 out. 1877, p.2 e 3. Biblioteca Nacional -RJ.
} 
pintura que pretendia solucionar justamente esse dilema: harmonizar o uso das imagens consideradas, "verdadeiras" da fotografia com a imaginação.

O fato novo e que incomodava os conservadores elitistas, é que o grande público já familiarizado com o padrão visual fotográfico, desejava ver na Pintura de História não invenções idealizadas e eruditas, mas cenas de um realismo "científico". Para atender essa demanda, Pedro Américo ao pintar o retrato do General Osório também apropriou-se de uma fotografia obtida durante a guerra no Paraguai. Esta imagem havia servido de modelo não só a Pedro Américo, mas a outros pintores, notadamente ao pintor francês radicado no Rio de Janeiro, Jean Courtois e a Joaquim Fragoso em 1870.

$\mathrm{Na}$ sua interpretação pictórica, Pedro Américo seguia a exatidão literal do retrato fotográfico que na época estava limitado somente aos tons pretos, brancos e cinzas. O pintor acrescentou as cores "naturais", cujo efeito final era um retrato mais realista do que a fotografia, a qual só produziria imagens coloridas no final do século XIX. Para este retrato, Pedro Américo buscou a aparência física "verdadeira", na exatidão literal da fotografia, acrescida dos sinais de tensão exigida pela narrativa da cena. O pintor modificou a direção do olhar do general Osório, transformando a frontalidade estática da fotografia em uma ação de sofrear o cavalo diante do perigo. O excesso de luz na fotografia - ocasionado pela forte luz solar ou pela luz oxietérica - dava um aspecto "achatado" e plano ao rosto, fazendo do retrato uma má fotografia até para os padrões da época. Isto obrigou Pedro Américo a reconstruir, manualmente, a forma volumétrica do crânio através do modelado de luz e sombra e da cor local da pele.

As fotografias encontradas na Biblioteca Nacional -RJ mostraram claramente que o retrato de Osório não foi o único em que Pedro Américo baseou-se para pintar a Batalha do Avahí. O Duque de Caxias, O Barão do Triunfo Andrade Neves, o General Câmara e outros oficiais retratados na Batalha também tiveram como modelo fotografias. É possível que o pintor tenha usado fotografias também para os batalhões de soldados, talvez conhecidos na época e hoje anônimos, assim como dos índios paraguaios. Com efeito, pode-se observar que os personagens não foram pintados idealizados. Para cada soldado retratado, o artista preservava a sua identidade. Esse trabalho escrupuloso em retratar um ser real baseado em "inartificiosas fotografias", como o próprio Pedro Américo definiu, claramente rejeitava a tradição renascentista italiana estabelecida como única pelas academias, a qual propunha uma narrativa totalmente idealizada. Foi observando, essa quantidade considerável de retratos individuais, o que 
levou uma boa parte da recepção crítica da época a celebrar a diferença "moderna" de Pedro Américo em relação à pintura idealizada da Batalha dos Guararapes, feita por Vitor Meirelles (acervo MNBA). Não foi por capricho que Pedro Américo havia se recusado a pintar essa batalha do século XVII, preferindo uma batalha recente, de 1868. Contava com a facilidade que existia para um pintor em encontrar os soldados e oficiais que ainda estavam vivos os quais poderiam fornecer um testemunho "verdadeiro" dos fatos históricos e, sobretudo, as indispensáveis fotografias. Além do mais, qualquer pintor,poderia facilmente comprar as fotografias dos "heróis da guerra", que eram vendidas pelos vários estúdios fotográficos no Rio de Janeiro. Essa nova prática no uso de fotografias para pintar um retrato, favorecia, sobretudo, a certeza da fidelidade ao modelo real dos principais personagens do conflito.

Outro ponto importante a destacar é a questão da ampliação das figuras e da rapidez de execução da obra, realizada praticamente em um ano .As fotografias de retratos dos personagens da guerra no formato carte-devisite $(6 \mathrm{X} 9 \mathrm{~cm})$ poderiam ser ampliados sem dificuldade, manualmente para uma tela , por um solitário pintor na pintura de cavalete. Mas em uma obra de grandes dimensões como a Batalha do Avahi, nada era espontâneo e necessitava de preparativos técnicos seguros para o bom resultado final da obra. O problema então, era resolver em um grande mural a exigência de "rapidez" de execução e "perfeição" realista dos fatos. Observe-se que a pintura contava com mais de 400 figuras e onde cada soldado estava retratado individualmente com grande quantidade de detalhes. Nossa hipótese é arriscada, mas seguindo fortes indícios, é bem possível que tenham sido feitos clichês em vidro destas fotografias para que fossem projetadas com a Lanterna Mágica, (um precursor dos modernos projetores de slides), a qual fazia as ampliações dos retratos na tela. A nossa hipótese de uso de instrumentos óticos, é reforçada pelo fato de que Pedro Américo conhecia bem o campo fotográfico, sendo amigo de um dos mais importantes fotógrafos cariocas, Marc Ferrez, com quem se aconselhava. O mais notável é que Marc Ferrez, era também um devoto das projeções luminosas de fotografias com a Lanterna Mágica em locais públicos, o que é um indício de que o pintor conhecia esses instrumentos. Essa hipótese em nada diminui a autoria criativa da obra. Essa era uma prática comum dos pintores murais da Pintura de História e principalmente dos populares Panoramas, os quais Pedro Américo conhecia bem, tendo visitado o Panorama de Londres, na Inglaterra. Em 1861,morando em Paris, deve ter visto o Panorama circular sobre a Guerra da Criméia (1855) Siége de 
Sebastopol pintado pelo Coronel Langlois, a partir de fotografias.Não eram fotografias comuns.Elas foram especialmente feitas na Criméia para servirem de modelo para a pintura. Os criadores dos Panoramas, para realizar com rapidez as gigantescas telas circulares, contratavam dezenas de pintores e projetavam desenhos e fotografias com a Lanterna Mágica. Este instrumento ótico era muito usado para facilitar o trabalho de ampliação e obter a máxima precisão na semelhança dos retratados e poderia ter sido utilizado por Pedro Américo.

Todos estes aspectos aqui esboçados em torno da Batalha do Avahi são uma tentativa de compreender Pedro Américo no seu real valor, como um mestre renovador do gênero da Pintura de História no Brasil. Costumase pensar a arte do séc. XIX, do ponto de vista dos artistas marginalizados dos Salons franceses, como os realistas e impressionistas e julga-se os pintores de história como esclerosados reacionários. Mas o Impressionismo francês, que ditaria os rumos de um novo modernismo nas artes com uma pintura de cavalete, anti-Pintura de História, só seria conhecido amplamente a partir de 1880. Van Gogh em 1979, ainda admirava o realista belga, De Groux e Seurat nada sabia sobre os impressionistas. As acusações de que a pintura de história era reacionária em oposição à vanguarda, só apareceriam a partir de 1890, com a palavra francesa pejorativa de "Pompier", ou seja, uma arte dramática como a ação dos bombeiros.

Portanto, antes dessa mudança estética, entre 1860 e 1880 Pedro Américo havia provocado um caminho novo para a Pintura de História no Brasil, conciliando imaginação e rigor fotográfico. E mais ainda. Como conceituou o próprio artista em um texto de 1864, a pintura deveria afastarse dos métodos das academias neoclássicas idealistas, como a defendida pelo pintor Ingres e estar voltada para as massas, inserindo-se na era do “espetáculo das artes”. Em 1877, Pedro Américo teve a audácia de por em prática essas idéias antiacadêmicas mandando fazer uma instalação da Batalha do Avahi em uma espetacular rotunda de Panorama onde hoje é a Praça XV, no Rio de Janeiro. Inaugurada com toda pompa em setembro de 1877, mais de um ano antes da exposição oficial na Academia, a mostra individual foi um acontecimento sócio-cultural sem precedentes no Brasil, tema que desenvolvemos em outro título.

A capital do império vivia assim, o cosmopolitismo do "espetáculo das artes" e deixava de ser conhecida apenas como uma "Bizâncio comercial".O artista que em março de 1877,já havia exposto a tela em Florença divulgada e comentada em cerca de 300 jornais, ajudava o país a projetar uma imagem de progresso e civilização no cenário europeu, digno 
das representações artísticas mais elevadas para a época ,como a Pintura de História. Pode-se compreender enfim, que com a grande repercussão da exposição e a polêmica aberta entre intelectuais na imprensa carioca entre 1877 e 1879, a pintura de Pedro Américo significava um exemplo moderno e cosmopolita do que esperavam ser a "Nova escola brasileira de pintura".

Nesse ponto, a sua pintura ocupou um significativo espaço de representação na sociedade brasileira e Pedro Américo tornou-se uma figura emblemática das aspirações nacionais por "emancipar a arte" do país. Foi nesse período histórico da chamada "era do espetáculo" que o artista respondeu aos desafios buscando soluções das mais avançadas. A história posterior, de uma cultura, como a brasileira, marcada por altas taxas de analfabetismo, revelaria por certo, muito da eficácia, do alcance e do impacto coletivo desta representação visual.
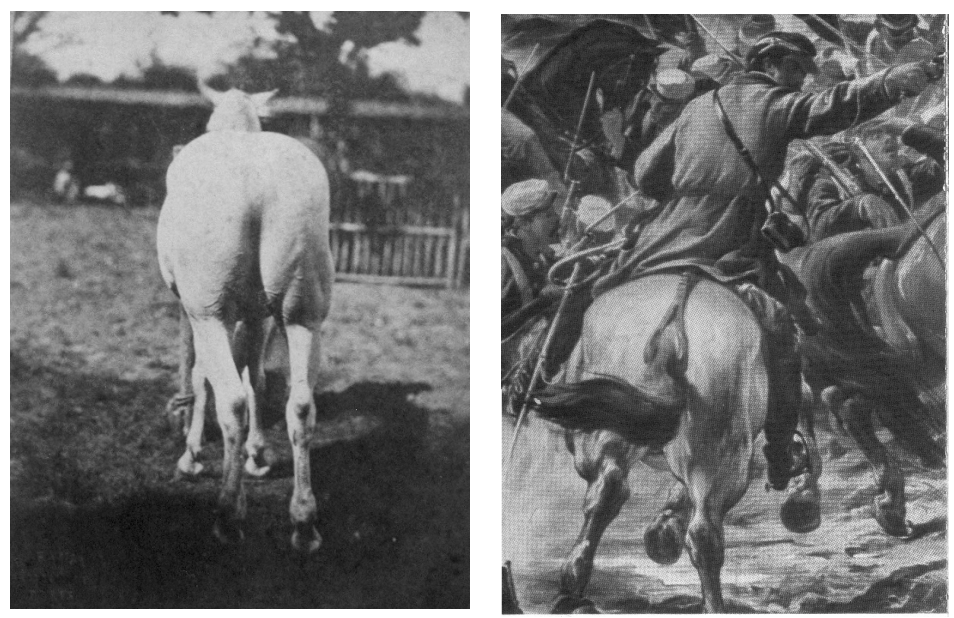

Este cavalo, sem dúvida, foi pintado a partir da fotografia ao lado, de um cavalo branco de costas, pertencente ao arquivo de Pedro Américo. O movimento do cavalo na Batalha do Avahí, pintado a partir dessa curiosa fotografia, criava uma imagem fora dos padrões idealistas da academia, causando grande polêmica em 1877. (Fotografia de "C. Famin- Photographe-Paris 12 X $15 \mathrm{~cm}$. Vendido na Photographie Artistique de A. Foucelle 6, Rue du Seine, 6 - Paris. Pasta 44, Arquivo MNBA-RJ) 


\section{Bibliografia}

BAJAC,Q.- L'image révélée -L'invention de la photographie - ed. Decouvertes Gallimard /Réunion des Musées Nationaux,Paris,França, 2001,159pp.:il.

FRIZOT,M. -Étienne-Jules Marey - Ed. Centre National de Photographie, Paris, França,1987, 140pp.:il

MACHADO,Vladimir: Fotografias e projeções Luminosas: os métodos fotográficos dos panoramas na pintura da batalha do Avaí de Pedro Américo: "o espetáculo das Artes". Edição do autor,RJ,2005, 83pp:il.

A fotografia na Batalha do Avai de Pedro Américo, Revista Nossa História, n.33, 2006,RJ.

A fotografia na pintura da Batalha do Avahí (Paraguay) de Pedro Américo in, "LATITUDES

Cahiers Lusophones,n.23, Brésil/Brasil -abril de 2005,104p. pp.35-40.:il. Numero dedicado ao Brasil ,durante o Ano Brasil na França.

OLIVEIRA, Vladimir Machado de: "Do Esboço pictórico às rotundas dos Dioramas: A fotografia na pintura de Batalhas de Pedro Américo ( 1843-1905) - Tese de Doutorado- Orientador: Prof.Dr.Elias Thomé Saliba. FFLCH-Universidade de São Paulo-Brasil-2002.283pp.:il.(arquivo digital e impresso).Depositado na Biblioteca Nacional,reg.n.333.486 livro:612,folha:146

ROUILLÉ, André-La photographie em France: Textes et controverses -1816-1860, ed. Macula, Paris, França, 1989.

HENDRICK,G. Eadweard Muybridge - the father of the Motion Picture, Dover Publications,Inc. 2001,271p.:iI. 